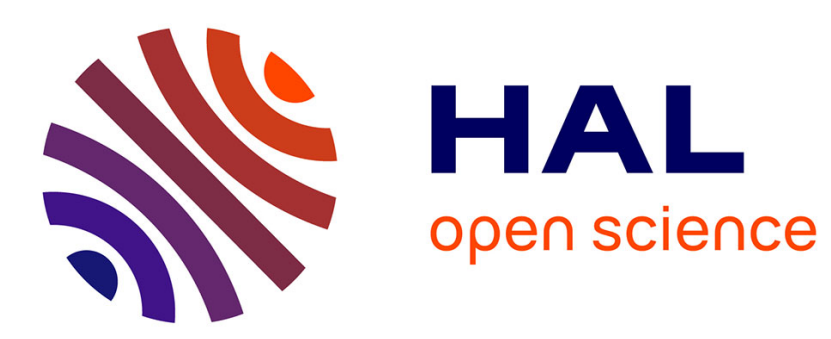

\title{
Fluid flow and mass transfer in a vacuum induction melting furnace
}

\author{
A. Jardy, D. Gosset, D. Ablitzer, S. Witzke
}

\section{To cite this version:}

A. Jardy, D. Gosset, D. Ablitzer, S. Witzke. Fluid flow and mass transfer in a vacuum induction melting furnace. Journal de Physique IV Proceedings, 1993, 03 (C7), pp.C7-1151-C7-1156. 10.1051/jp4:19937179 . jpa-00251810

\section{HAL Id: jpa-00251810 https://hal.science/jpa-00251810}

Submitted on 1 Jan 1993

HAL is a multi-disciplinary open access archive for the deposit and dissemination of scientific research documents, whether they are published or not. The documents may come from teaching and research institutions in France or abroad, or from public or private research centers.
L'archive ouverte pluridisciplinaire HAL, est destinée au dépôt et à la diffusion de documents scientifiques de niveau recherche, publiés ou non, émanant des établissements d'enseignement et de recherche français ou étrangers, des laboratoires publics ou privés. 


\title{
Fluid flow and mass transfer in a vacuum induction melting furnace
}

\author{
A. JARDY, D. GOSSET, D. ABLITZER and S. WITZKE* \\ LSG2M, URA 159 du CNRS, Ecole des Mines de Nancy, Parc de Saurupt, 54042 Nancy cedex, France \\ * IMPHY S.A., 58140 Imphy, France
}

\begin{abstract}
In order to control the composition and the inclusion content of a vacuum induction melted maraging steel, an experimental and theoretical study was undertaken to characterize the hydrodynamic behaviour and the transport of elements dissolved in the liquid metal. The bath movement due to stirring forces was calculated with the aid of a model which then determines the transfer characteristics of a solute, due to molecular diffusion, convection and turbulence. Particular attention was given to the phenomenon of volatilization at the free surface. The results obtained using this approach are presented and discussed.
\end{abstract}

\section{INTRODUCTION}

The maraging steel Marphy 17 is an age-hardening martensitic iron-based alloy with a very low carbon content, possessing high tensile strength, excellent toughness and very good weldability. Its applications also require a high fatigue strength. In particular, it is used for the manufacture of turbine and compressor shafts for commercial aircraft engines, which are severely loaded in service. The fatigue properties of these critical rotating components are determined by careful control of the alloy composition and inclusion content.

During melting in the vacuum induction furnace, the final stage of deoxidation forms alumina inclusions, whose presence in the alloy would have harmful effects on the mechanical properties. In order to avoid this problem, calcium additions are made to the liquid metal (in the form of $\mathrm{Ni}$-Ca), transforming the solid alumina inclusions to liquid calcium aluminates, the reaction products being more readily removed from the bath.

However, the calcium treatment involves secondary reactions such as the loss of part of the calcium by volatilization from the bath surface, and the reaction of the calcium-containing metal with the refractory lining of the furnace crucible $\left(\mathrm{Al}_{2} \mathrm{MgO}_{4}\right.$ spinel). Excessive transfer of magnesium to the inclusions can render them solid and harmful again.

All the parameters of this treatment must therefore be perfectly controlled in order to ensure the required metal quality. The aim of the present study was thus to develop a model of the variation of the composition and inclusion content of the liquid metal as a function of the operating conditions, taking into account the hydrodyriamics of the bath and the reactions at the interfaces. This work forms part of a wider endeavour to understand and to model refining reactions in metallic alloys, in order to improve process control. To attain this objective, it was necessary to use a mathematical model of the hydrodynamic behaviour of the metal bath, followed by a simulation of solute transport in the transient regime. These models were validated by tests in both laboratory $(50 \mathrm{~kg})$ and industrial $(6 \mathrm{t})$ furnaces. 


\section{HYDRODYNAMIC BEHAVIOUR OF THE LIOUID METAL IN THE VIM FURNACE}

\section{II.1. Description of the model}

In the VIM furnace, the movement of the liquid metal is due essentially to stirring (or Lorentz) forces created by the interaction between the alternating magnetic field induced by the copper crucible winding coils and the currents produced in the metal by the electromotive force resulting from the fluctuations in magnetic induction.

The Lorentz forces in both the $50 \mathrm{~kg}$ and $6 \mathrm{t}$ furnaces have been calculated by Y. Fautrelle (Madylam), based on the furnace/induction coil geometries and the electrical parameters usually employed. The characteristics of the movement of the liquid metal under the action of these force fields could then be determined. The model which has been developed is based on the use of the finite volume method to numerically solve the Navier-Stokes equations in secondary variables (turbulence and current function), in the steady state regime and for an axisymmetrical geometry [1]. The bath temperature is assumed to be uniform, so that natural convection is neglected. The method takes into account the intensity of turbulence with the aid of the coupled $\mathrm{k}-\varepsilon$ model [2].

The solution of the Navier-Stokes equations and the constitutive equations of the turbulence model requires the mathematical expression of the boundary conditions, which represent the physical phenomena at the different interfaces:

- axial symmetry,

- logarithmic decrease to zero at the crucible walls of the velocity and turbulence,

- decrease of the tangential friction and turbulence to zero at the free surface [3].

This last condition is particularly important, since the velocity calculated at the free surface, where it is very sensitive, is the principal criterion for the validation of the hydrodynamic model (see below).

\section{II.2. Results of the model}

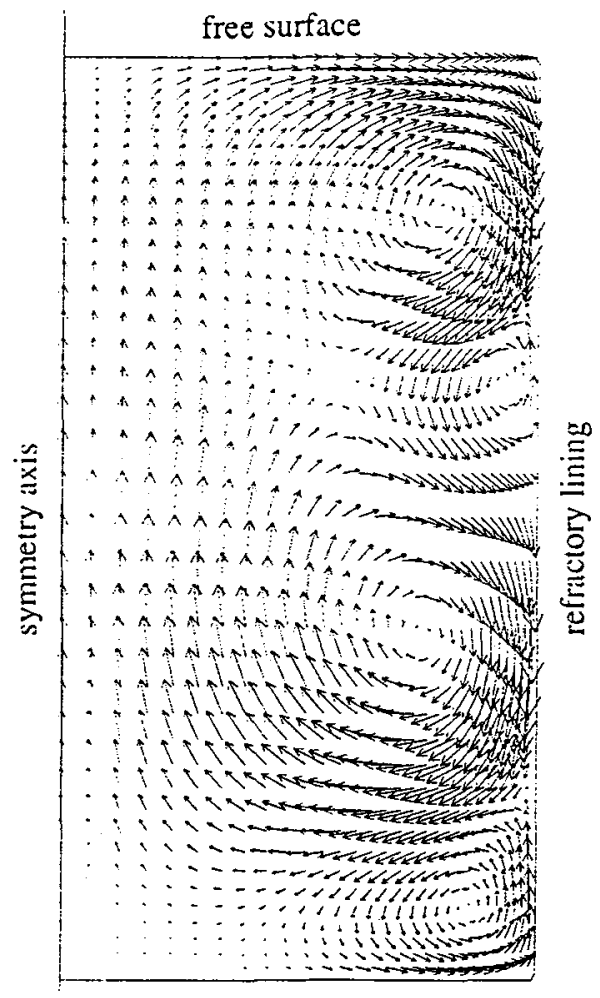

Based on the electromagnetic force fields in the $50 \mathrm{~kg}$ laboratory furnace and the $6 \mathrm{t}$ industrial furnace, the model enabled calculation of the velocity fields, together with maps of the intensity of turbulence. The spatial mesh employed was progressively refined until the results were no longer modified. In the case of the $50 \mathrm{~kg}$ furnace, the velocity field presents two recirculation loops in the diametral plane : a first large vortex, which entrains the majority of the liquid metal, and a second smaller one. situated near the bottom of the crucible.

The existence of two vortices is due to the position of the inductor. The middle of the coil (maximum Lorentz forces) corresponds to the zone of separation between the two vortices. This effect has already been observed $[4,5]$. The highly turbulent movement is centrifugal at the free surface.

In the $6 \mathrm{t}$ furnace, the Lorentz force field, due to the association of three separate coils, leads to a complex movement, which is also turbulent, illustrated in figure 1.

figure $1:$ Velocity field in the $6 \mathrm{t}$ furnace $\left(\mathrm{V}_{\max }=38 \mathrm{~cm} / \mathrm{s}\right)$. 


\section{II.3. Validarion of the model}

The validation of the hydrodynamic model is based on the comparison of the displacement of particles placed on the surface close to the symmetry axis with the calculated movement of the liquid metal.

The position of the particles is measured every $1 / 25$ th of a second from video images of the bath surface in the $50 \mathrm{~kg}$ laboratory furnace. The experiments were performed under argon at atmospheric pressure, for three power levels $(27,49$ and $90 \mathrm{~kW}$ ) and three types and/or diameters of balls ( 2 and $5 \mathrm{~mm}$ diameter nickel balls and $2 \mathrm{~mm}$ diameter alumina balls).

Figure 2 shows two examples, in which the positions of a ball measured as a function of time are compared to the displacement of a fluid particle calculated from the model. The time $t=0$ corresponds to the position of the ball in the first observation. In both cases, excellent agreement is obtained between the experimental and calculated behaviour, although the curvature of the free surface and the real nature and size of the particle are not presently taken into account by the model.

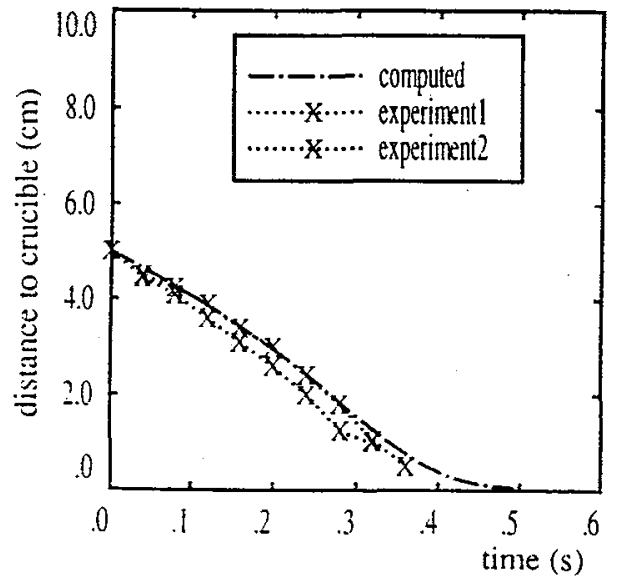

a) $5 \mathrm{~mm} \mathrm{Ni}$ ball, $27 \mathrm{~kW}$

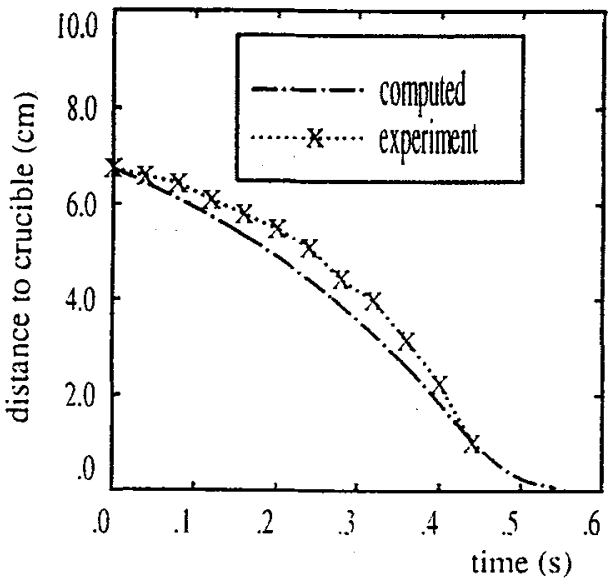

b) $2 \mathrm{~mm}$ alumina ball, $49 \mathrm{~kW}$.

figgure 2 : Validation of the hydrodynamic model.

\section{SOLUTE TRANSPORT AND VOLATILIZATION}

\section{1. Description of the model}

In an initial simplified approach to the study of solute transport during the melting of metallic alloys in the VIM furnace, a model was developed which neglects the interactions between the liquid metal and the refractory lining. Moreover, the results presented in this section do not take into account the presence of dissolved oxygen and therefore the formation of oxide inclusions. In these conditions, it can therefore be considered that there is no interaction berween the different solutes. Consideration of the thermodynamic equilibrium with a dispersed phase composed of oxides will be treated in the next section.

With these assumptions, the solute transfer can be described by the equation :

$$
\frac{\partial \omega_{\underline{A}}}{\partial \mathrm{t}}+\vec{\nabla}\left(\omega_{\underline{\mathrm{A}}} \overrightarrow{\mathrm{V}}\right)=\vec{\nabla}\left(D_{\mathrm{A}, \mathrm{eff}} \vec{\nabla} \omega_{\underline{\mathrm{A}}}\right)
$$

where $\omega_{\underline{A}}$ is the weight percent of element $A$ in solution.

The velocity at any point $\vec{V}$ and the effective diffusion coefficient $D_{A, \text { efr, which depends directly on }}$ the intensity of the turbulence, are obtained from the hydrodynamic model described above. 
In order to take into account the volatilization of metallic elements such as calcium or magnesium, which have a high vapour pressure, the model uses as a boundary condition the Langmuir law, which describes the thermodynamic equilibrium at the interface for the low pressures of the gaseous phase, and assumes that the metallic vapours condense on the furnace walls. It can be written in the form :

$$
\varphi_{\underline{A}}=-\alpha a_{A} P_{A}^{\circ} \sqrt{\frac{M_{A}}{2 \pi R T}}
$$

where $\quad \varphi_{\underline{A}}$ is the mass flux density at the surface $\left(\mathrm{kg} / \mathrm{m}^{2} . \mathrm{s}\right)$

$a_{A}$ is the Raoultian activity of the dissolved element $A$

$\mathrm{P}^{\circ} \mathrm{A}$ is the vapour pressure of element $\mathrm{A}$ at temperature $\mathrm{T}(\mathrm{Pa})$

$M_{A}$ is the molecular weight of element $\mathrm{A}(\mathrm{kg} / \mathrm{mole})$

$\mathrm{R}$ is the universal gas constant $(\mathrm{J} / \mathrm{kg} . \mathrm{K})$

$\mathrm{T}$ is the temperature at the surface $(\mathrm{K})$

$\alpha$ is the condensation and/or retrodiffusion coefficient $(0 \leq \alpha \leq 1)$.

The partial differential equation is solved by a totally implicit finite volume method. The results of the model are presented in the form of iso-concentration curves for the dissolved elements as a function of time. The variation of the mean composition can then be readily calculated from the model.

\section{2 Results of the matter transfer model}

The model was used first of all to characterize the efficiency of stirring in the VIM furnace, by calculating the homogenization of the bath, for example with respect to calcium, without considering volatilization (i.e. taking $\alpha=0$ ). The initial condition corresponds to the introduction of a calcium-rich zone at the center of the bath, in order to simulate the addition of a lump of $\mathrm{Ni}-\mathrm{Ca}$.

In both the laboratory and industrial furnaces, mixing is extremely rapid, the characteristic time being of the order of $5 \mathrm{~s}$ for the $50 \mathrm{~kg}$ furnace and $20 \mathrm{~s}$ for the $6 \mathrm{t}$ furnace. Furthermore, experimental measurements on the laboratory fumace showed that solid lumps of Ni-Ca dissolved in less than 3 minutes. In the light of these results, it seemed reasonable to impose as an initial condition a uniform composition in the liquid metal, and this was done in the calculations described below. In the absence of interfacial reactions and surface volatilization, the homogeneity of the liquid bath in the VIM furnace has been confirmed by measurements of the kinetics of dissolution of lumps of copper in liquid iron.

The calculations presented in the remainder of this article take account of transfers at the liquid/gas interface. Considering the relatively high pressure (1-270 mbar) prevailing in the furnace during melting of Marphy 17, the value of the retrodiffusion coefficient $\alpha$ is different from 1 , and has an important effect for the elements whose vapour pressures are not very high. An indirect measurement of $\alpha$ was therefore made for a solution of about $1 \%$ of manganese in liquid iron in the $50 \mathrm{~kg}$ fumace. The choice of this system was based on the fact that no disturbing secondary reaction is to be feared in this case. The tests were performed at different argon pressures $(2,20$ and $270 \mathrm{mbar})$ at $1600^{\circ} \mathrm{C}$. The variation of manganese content with time, determined by $X$-ray fluorescence analysis, enables the retrodiffusion coefficient to be calculated, by comparison with the results of the simulations (in terms of the mean concentration of the bath). This approach and the results obtained are represented in figure 3.

If it is attempted to directly apply similar values to the case of calcium and magnesium vaporization during the melting of Marphy 17 , it is found that a large variation in $\alpha$ (from 1 to 0.01 ) has only a very slight effect on the average concentration. In effect, these two elements have very high saturation vapour pressures at the temperatures involved (about $1520^{\circ} \mathrm{C}$ ), and the overall kinetics of volatilization are controlled by transfer from the bath to the free surface.

Samples taken from the $50 \mathrm{~kg}$ and $6 \mathrm{t}$ furnaces during melting were analyzed by $\mathrm{X}$-ray fluorescence in order to determine the calcium content after the addition of $\mathrm{Ni}$-Ca. Figure 4 shows the calculated variation of the mean calcium content in the bath, together with the few experimental points available for the initial instants. 


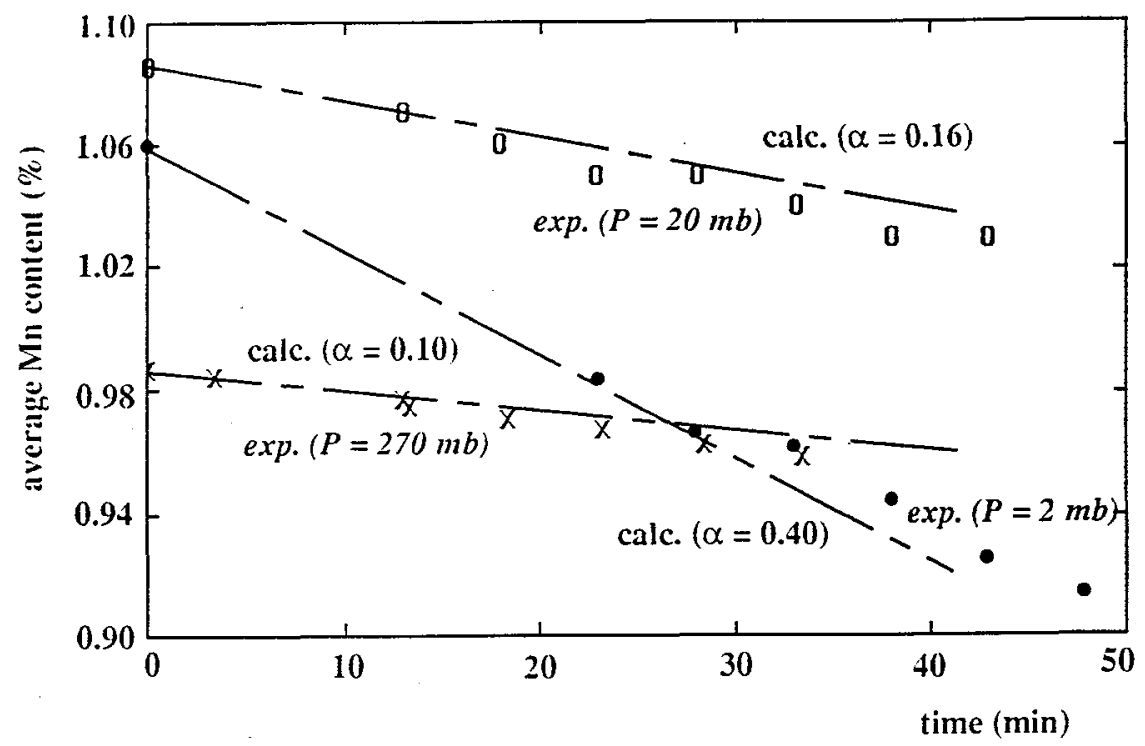

figure 3 : Determination of $\alpha$ as it function of the pressure by comparison between calculation and experiment. Volatilization of $\mathrm{Mn}$ in liquid Fe.

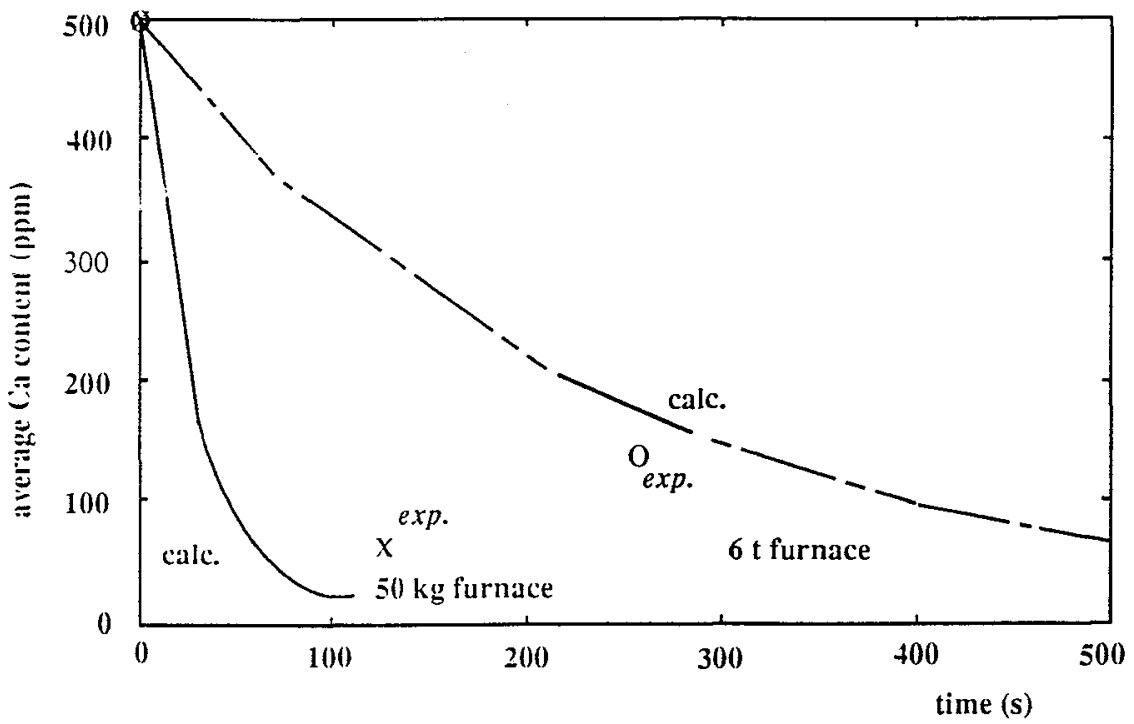

figure $4:$ Variation of the average calcium content as a function of time.

As already been said. the value of the parameter $\alpha$ has very little influence on the results of these last calculations. Although good general agreement is observed, it must not be forgotten that the interactions between the elements dissolved in the metal, the refractory lining and, obviously, oxide inclusions, also play an extremely important role.

\section{FOR.MATION OF INCLUSIONS IN THE LIOUID METAL}

In order to represent the equilibrium berween the liquid metal and the dissolved elements ( $\mathrm{Al}, \mathrm{Ca}$, $\mathrm{Mg}, \mathrm{O})$ on the one hand and the oxide inclusions formed on the other hand, the thermodynamic model developed by IRSID and used successfully $|6|$ to describe the precipitation of inclusions within a bath of 
liquid metal or during solidification was employed. The composition of the oxides is modified until the oxygen activity becomes equal in the different phases. Thermodynamic equilibrium is then automatically verified. Based on the "overall" concentrations $\omega_{\mathrm{Ca}}, \omega_{\mathrm{Al}}, \omega_{\mathrm{Mg}}$ and $\omega_{\mathrm{O}}$, together with the composition of the alloy, it is thus possible to determine the weight percentages of the dissolved elements, the weight percentages of the elements "tied up" in the form of oxide inclusions, and the nature and composition of these inclusions.

This model enables characterization of the equilibrium between a homogeneous bath and a system of oxides. It is possible to combine it with the matter transfer model which calculates the composition of the liquid metal as a function of time and position. The coupling is based on the assumptions that the inclusions are immobile (no transport of the oxide phase and no decantation phenomena) and that local thermodynamic equilibrium exists at all times between the metal and the inclusions. The kinetics of inclusion formation and dissolution are thus considered to be infinitely rapid. In these conditions, the thermodynamic equilibrium model represents a subroutine of the matter transfer model, which is called up for each mesh point at each time increment.

The first results obtained with this approach show qualitatively the effect of the formation of inclusions, which, by tying up a large proportion of the total calcium, considerably reduce the driving force for volatilization, which is proportional to the activity of dissolved calcium. For this reason, the overall rate of calcium evaporation is markedly reduced. In the continuation of this work, a major goal will naturally be the consideration of interactions with the refractory lining.

\section{CONCLUSIONS}

The results obtained in the course of the present study should now enable the interaction between the liquid metal and the refractory furnace lining to be taken into account. This represents the last step in the procedure, and should rapidly lead to a global model for predicting the composition and inclusion content. Indeed, the results already provide considerable insight into a complex industrial process. The major points established are :

- the hydrodynamics of the industrial and laboratory furmaces,

- confirmation of the rapid homogenization of calcium in the molten bath,

- the control of calcium and magnesium evaporation kinetics by transport in the liquid phase,

- the variation of inclusion composition in the absence of reactions with the refractories.

From a scientific standpoint, the competence developed during this work will be applied to other melting processes, where the transfer of matter in liquid metals, together with gas/metal reactions, play a predominant role.

References

[1] HERRERA M., JARDY A., ABLITZER D., Proc 11th I.C.V.M., eds S.F.V., (1992) 13.

[2] LAUNDER B.E., SPALDING D.B., Comp. Met. Appl. Mech. Eng. 3 (1976) 269.

[3] LEVICH V.G., Physicochemical hydrodynamics, eds Prentice-Hall Inc., (1962).

[4] EVANS J.W., LYMPANY S.D., Metall. Trans. 14B (1983) 306.

[5] EL KADDAH N. et al., Metall. Trans. 17B (1986) 687.

[6] GAYE H. et al., Mem. Sci. Rev. Met. 86 (1989) 237. 